most important regions on the planet. And the conservation response - marine protected areas (MPAs) - should be a key tool to safeguard the world's maritime environment. By setting aside areas in which human activity is tightly regulated, the thinking goes, governments can ensure that key habitats and species are preserved.

Certainly, good MPAs such as those in Hawaii and around the Great Barrier Reef can bring great benefits, from saving individual species from extinction to preserving entire coral-reef or deep-sea ecosystems. And the number of these areas is on the rise, as the world's governments crawl towards a target to protect $10 \%$ of the oceans.

But to get the most from these areas, much greater efforts are needed. In the sea, as on land, balancing the recommendations of scientists with commercial needs and other interests is always tricky for politicians. Still, as highlighted on page 166, and as shown by recent developments in Australia (see Nature 480, 14-15; 2011), there are growing concerns about the poor science base of many of the existing and proposed MPAs.

As Australia divides up its waters into a patchwork of protected, recreational, commercial and multipurpose areas, researchers say that the country is ignoring evidence that would make this zoning stronger. These concerns, which surfaced over proposals for the southwest region, again in the northwest region and then most recently in the plan for a huge reserve in the Coral Sea, centre on whether enough sea has been given the highest level of protection and whether the areas that are highly protected include a representative selection of all necessary habitats. The second question in

particular is one on which the voices of researchers must be heard by government, and acted on.

And even when reserves are established on the basis of sound science, governments must ensure that they can protect the areas properly. It is telling that even the prosperous United States may be

"Declarations of protection are worthless without actions and, crucially, without money." failing in this. Jane Lubchenco, the head of the US National Oceanic and Atmospheric Administration, says: "We don't have the resources that we need to actually monitor, enforce and understand these areas." If the United States is having trouble, what hope is there for the less-developed nations?

In the sea, as on land, declarations of protection are worthless without actions and, crucially, without money.

Equally, governments must not fall into the trap of thinking that designating and protecting a certain percentage of our seas will solve all maritime conservation problems. Larger efforts to reform our approach to the oceans, from fisheries to extraction, are long overdue. Efforts in New England waters have demonstrated that it might be possible to manage local fisheries sustainably (see Nature 465, 540-542; 2010), and international agreements - such as those that have safeguarded Antarctica - show that countries can pull together under the right circumstances. For too long what has been out of sight has also been out of mind. The rise of MPAs should be a starting point for a reformation, not a tool to hit a target so that we say 'job done' and move on to other issues.

\section{A massive comfort}

\author{
There are bigger things in the Universe than \\ our earthly worries. Much bigger.
}

$\mathrm{P}$ eople have always looked to the heavens for inspiration and distraction from everyday life. Some see their futures in the stars and others talk to the man in the Moon. But for the really big problems, you need a really big distraction. So for readers who feel especially gloomy, perhaps about the latest bout of political shadowboxing on global warming in Durban, South Africa, or the perilous state of European finances, let Nature introduce you to two newly identified black holes. These are not the ordinary, twoa-penny stellar black holes, mind, but their supermassive relatives - the big beasts of the cosmos.

On page 215 of this issue, astronomers from across the United States present their discovery of the two most massive black holes ever found. The larger of the pair would tip the scales at some ten billion times the mass of our own Sun. Heavy stuff indeed.

In some respects, it is surprising that these black holes have managed to hide for so long. The curious twinkling of some quasars dated to the earliest days of the Universe had made astronomers pretty sure that the giants were out there somewhere, yet the previous heavyweight champion, in the giant elliptical galaxy Messier 87 , is a relatively puny 6.3 billion solar masses.

Measuring the motion of stars from two different galaxies that are the biggest in their clusters, NGC 3842 and NGC 4889, Nicholas McConnell of the University of California, Berkeley, and his colleagues found that NGC 3842 has a central black hole with a mass of 9.7 billion solar masses, and NGC 4889 has a black hole about the same size or even larger. (All massive galaxies with a spheroidal component, such as the bulge of the Milky Way, are thought to harbour a supermassive black hole at their centre.)

As celestial inspirations go, it is true that the giant twins of darkness at the heart of NGC 3842 and NGC 4889 are somewhat distant companions. The nearest is about 98 megaparsecs from Earth — about 320 million light years. And it is true that McConnell's team was able to look to the sky with more than a shrug of resignation - the researchers could use integral-field spectrographs at the giant Gemini North and Keck telescopes perched on Hawaiian mountains. But what these supermassive black holes lack in touchy-feely access, they surely gain in being really, really big. And if it helps those of us weighed down by terrestrial matters, they are out there, somewhere.

As supermassive black holes go, they are perhaps just a little too supermassive, certainly a bit larger than astronomers would have predicted given what they know about their host galaxies. Perhaps the processes that influence the growth of the largest galaxies and their black holes are somehow different from those in smaller galaxies? As the authors note, better adaptive optics instruments on telescopes and very-long-baseline radio interferometry are finding black holes in ever more exotic galaxies, and will help to answer that question.

It now seems plausible that, within a decade or so, astronomers will be able to capture the first direct image of a black hole. Plans are afoot to link a network of instruments, stretching from the high desert plains of Chile and the South Pole to potential sites in Africa and New Zealand. Pointed at the centre of our own galaxy, such a telescope should be able to see SgrA*, the supermassive black hole believed to sit there. Astronomers already have an image in mind: a bright ring spun around a dark shadow cast by the black hole, because no light escapes its event horizon.

Widely described as the point of no return, the event horizon of $\mathrm{SgrA}^{\star}$ would be the largest in our skies, but still just 30 microarcseconds across - the apparent size of a tennis ball on the Moon when viewed from Earth. To capture its image would be a stunning technical achievement in itself, but it would also open the door to further studies of how black holes spin and gather material, as well as probing some fundamental aspects of space-time and general relativity. And the first picture taken of our local supermassive black hole - the most enig- $\rightarrow$ NATURE.COM To comment online, click on Editorials at: go.nature.com/xhunqu matic and charismatic of all the wonders of the Universe - would surely be one of the defining images of the time. It might even knock everyday trouble and strife from the front pages, and perhaps even, for a while, from people's minds. 